\title{
Sustainable production of forest biomass for energy
}

\author{
by J. Peter Hall ${ }^{1}$
}

\section{Introduction}

There is a growing global awareness of the many values of forests; protecting soils from erosion, ensuring a steady supply of water; providing a habitat for plants and animals (thus maintaining biodiversity), and supplying wood for a variety of structural, domestic and industrial products. Forests absorb carbon dioxide from the atmosphere, and are valued for aesthetic, spiritual, cultural and traditional values for rural and urban dwellers alike.

Forests are a source of energy through the conversion of woody biomass into convenient solid, liquid or gaseous fuels to provide energy for industrial, commercial or domestic use. Already forests provide about $14 \%$ of world primary energy supplies, and forests have the potential to meet up to $50 \%$ of world energy demands during this century. About $55 \%$ of the 4 billion $\mathrm{m}^{3}$ of wood used annually by the world's population is used as fuelwood or charcoal directly to meet daily energy needs of heating and cooking, mainly in developing countries. Large quantities end up as waste from industrial processes such as black liquor, the lignin-rich residue of the pulp and paper industry used to generate heat, steam and electric power.

Energy and bioenergy are becoming increasingly interesting and important subjects for the public, policymakers and decision-makers as a result of rises in the prices of fossil-derived energy, coupled with an aversion to the use of nuclear energy. Enhanced environmental concerns are encouraging alternative and renewable sources of energy, particularly in developed countries. National governments are beginning to respond to the United Nations Framework Convention on Climate Change (UNFCCC) that created the Kyoto Protocol. The Protocol is stimulating policy directed towards the limitation of emissions, and the trading of carbon credits to reduce the concentration of greenhouse gases, particularly carbon dioxide $\left(\mathrm{CO}_{2}\right)$.

The two main causes of rising $\mathrm{CO}_{2}$ concentrations are burning of fossil fuels, and land-use changes, particularly deforestation. During the $1990 \mathrm{~s}, 6.3$ gigatonnes of $\mathrm{CO}_{2}$ was produced annually from fossil fuels, 3.3 gigatonnes/yr was emitted into the atmosphere with the rest taken up by vegetation and the oceans. Burning fossil fuels releases $\mathrm{CO}_{2}$ that has been locked up for millions of years. Burning biomass simply returns to the atmosphere the $\mathrm{CO}_{2}$ that was absorbed as the plants grew and there is no net release of $\mathrm{CO}_{2}$ if the cycle of growth and harvest is sustained. By substituting for fossil fuels land used for biomass and bioenergy production can potentially continue to provide emissions reductions indefinitely.

Deforestation and land use changes accounted for 16.1 million hectares of forest converted. The obvious solution then revolves around the reduction of carbon dioxide emissions,

Key words: biomass, bioenergy, harvesting, short-rotation crops, rural development, sustainability

${ }^{1}$ Canadian Forest Service, Natural Resources Canada, 580 Booth St., Ottawa, Ontario K1A 0E4. E-mail: phall@NRCan.gc.ca and reversing trends toward deforestation and by afforesting barren lands. This process is being encouraged by two trends. Changes in agricultural policies of many countries is resulting in additional land becoming available for nonagricultural crops. This means that more land is available for growing other crops, particularly biomass. Secondly, technological changes in the manufacture of wood products is

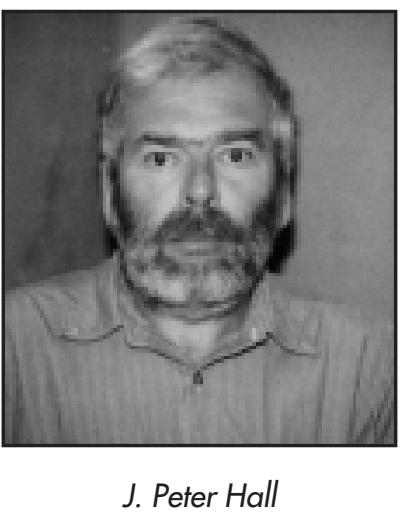
increasing the range of types of fibres that can be processed. This increases potential demand for different types of biomass feedstocks and consequently for increased use of bioenergy as the commercial market expands.

Biomass resources therefore, consist of conventional forestry and agricultural crops, energy crops, herbaceous, woody, oil-bearing plants, wastes and residues. Biomass production systems often use biomass that would otherwise be unmerchantable. Harvesting, handling and collection technologies are in the early stages of development but will not proceed further in the absence of demand-driven fibre. Conversion of biomass may involve various processes; biochemical, thermochemical, physical/chemical. The end products consist of transportation fuels (ethanol and biodiesel), heat and electrical power.

This paper discusses issues associated with the sustainability of biomass production systems for the production of energy:

1. The cost of producing biomass, silviculture, forest management, harvesting, transportation, and the impact of various economic factors;

2. The need for environmental sustainability, and how biomass can be produced without impacting negatively on the land base;

3. The relationship between biomass production and people or social and cultural issues.

Sustainability, the common principle, combines economics, environment, and social/cultural considerations. Sustainability in relation to the management and use of the forest involves ensuring that what we do in the forest and the benefits we derive from forests today do not compromise the opportunities for future generations to similarly benefit. Forest biomass can be a sustainable source of energy - a valuable renewable alternative to finite fossil-based energy sources, but only if the principle of sustainability is maintained. The focus of bioenergy initiatives is that the use of forests for energy be efficient, economic and environmentally sustainable.

\section{Biomass Production from Forestry}

Biomass is produced from conventional forestry systems where biomass for energy is a by-product of timber production systems. The normal life-cycle of forests in conventional forestry systems begins with regeneration, through the sapling stage of 
rapid height growth, the intermediate stage of steady growth in diameter/height/volume, finally reaching maturity/harvest, and continuing to the regeneration stage, a period of 30-80 years. The forest "stand" may be as small as the area of a single mature tree in a selection-managed mixed forest, or hundreds of hectares of single-species, fire-origin boreal forest.

Forest operations may be conducted at each stage of the rotation; thinning operations in young stands provide more growing space for the remaining trees and yield wood fibre suitable for energy. Thinning in older stands yields poles, pulpwood, and the tops and branches can be used for bioenergy. Final harvests yield a range of products including those suitable for bioenergy. Stands damaged by insects, disease or fire may also provide biomass suitable for conversion to energy. Residues usually constitute $25-45 \%$ of the harvested volume of wood so implementations of biomass production systems may be a significant part of forest management decisions. Bioenergy is seldom the sole consideration in forest management decisions, but forest operations can be modified to recover biomass and integrated operations greatly enhance operational efficiency. Cost-effective handling of biomass requires careful harvesting, avoiding contaminants and promoting drying of the material yielding lighter residues with higher energy values. A variety of harvesting and transportation equipment has been developed for different forest conditions and scales of operation.

There are ancillary benefits from harvesting biomass since removing residues from the site facilitates access for site preparation and planting. Removal of the residues lowers the risk of fire and damage from insects and diseases. In assessing the economic sustainability of a biomass harvesting systems these costs and benefits must be considered.

Forest residues normally have low density and fuel values so biomass is most economically converted to other energy close to source. Transport costs may be reduced if biomass density is increased before transportation. This may be achieved by comminution (reducing residues to small pieces with a chipper, grinder or a flail), or by compaction (compressed/cut bundles of uniform size) termed compact residue logs (CRLs) that can be efficiently handled. If the end product, biomass-produced fuel, becomes more valuable, transportation costs may eventually be less limiting to increased biomass use.

Considerable success has been achieved in Canada by the large-scale use of mill wastes (sawdust, bark, chips, shavings, etc.) in energy generation. This has continued to the point where nearly all available fuels are being used in this fashion. Similarly fuelwood stands contribute to much domestic heating in rural areas, but little data are available to estimate the extent.

If the residues are used for heating, the material is stored/dried and supplies linked to peak heating periods. Storage may take place at the stump, piles (comminuted or uncomminuted), at roadside, central terminal, or at the conversion facility. The choice is governed by biological, economic and logistical considerations. Costs vary greatly among production systems according to cost of cutting, stacking, chipping, forwarding to roadside, truck transportation and administrative overhead.

\section{Biomass Production from Plantations}

Conventional forestry production systems are one source of woody biomass for energy; dedicated energy crops are another. The latter are usually short-rotation (3-15 years) plantations of poplar, (Populus) willow, (Salix) or agricultural crops con- sisting of annual or perennial grasses (Miscanthus). The tree species of interest are relatively more demanding in terms of nutrient and water requirements and cultural treatments than most conventional forest species, although a wide range of forest species are being, or have been, tested for suitability in biomass plantings. The production systems are more akin to agriculture than conventional forestry, and agricultural production systems are usually needed for the species to achieve their growth potential. Production systems begin with thorough site preparation (involving ploughing, discing, harrowing, herbicide application) to manage weed competition. Once the site is prepared it is then planted in spring, usually with dormant cuttings of willow or poplar, about $20-25 \mathrm{~cm}$ long. Planting methods are commonly by machine (purpose-built) with production rates of $1 \mathrm{ha} / \mathrm{hr}$. Weed control is usually necessary during the first year, fertilizaton during the second and future years depending on soil/site conditions and crop requirements. The stems (of willows) may be cut back after the first growing season to stimulate sprouting and so maximize production of biomass during the second and subsequent years. The crop is usually harvested after three years (willow) or 10-12 years (poplar) where yields of 12-18 ODT/ha/yr can be expected. Yields measured on a variety of sites in the northern hemisphere indicate that operational expectations of $\sim 15$ tonnes/ha. Are realistic. Harvesting usually occurs in the winter using purpose-built harvesting equipment or modified standard equipment. As the production systems become more widespread, machine development is expected to accelerate. Harvested stems are often converted to chips on the site and then transported to the conversion plant.

After harvesting, the cut willow stumps are left to sprout and re-grow another crop to be harvested after three years, and the process continued for several rotations. Single stem plantations, such as poplars, have to be replanted after each harvest. During the rotation, constant attention must be devoted to the maintenance of nutrient/water levels, management of pests and diseases, all of which can reduce yields if not managed properly.

In many parts of the world, crop improvement through selection and breeding is underway to select and test species and clones combining fast growth, tolerance to pests and diseases matched to particular site and soil conditions.

It is possible to manage land simultaneously as a carbon sink and for the production of solid wood products and for biomass for energy. New energy crops/forests planted on abandoned agricultural land can increase species biodiversity where species cover was previously poor as is usually the case when a single agricultural crop is grown.

The trade-offs between production needs, carbon sink enhancement and biodiversity are facilitated through the use of inherent genetic diversity in planting stock, and creating a patchwork of crops and ages to create structural diversity.

Policy initiatives are being used to stimulate the increased use of biomass for energy generation. For instance, in the UK there is an obligation to target $10 \%$ of electricity (from a current $3 \%$ ) supply from renewables by 2010 , a policy that will stimulate growth in biomass use. Such considerations can have significant impacts on the environment since changes in land use will require considerable public acceptance in more urbanised societies. A 30-MW power station which is enough to supply electricity for 30000 houses, needs 11250 hectares, assuming production of $10 \mathrm{ODT} / \mathrm{ha} / \mathrm{yr}$. In the US there are sev- 
eral energy generation projects that use a proportion of shortrotation-crop biomass with coal to produce electricity. The use of biomass is increasing both in terms of public acceptance and economic oppportunity. Use of biomass for energy generation is now part of the public policy agenda, with different levels of government, the private sector, universities and research establishments all involved. Past policy initiatives in Sweden have promoted the use of biomass in district heating so that by 1996 about $25 \%$ of district heating in Sweden was from biofuels, a source that is increasing at the rate of 3-4 Twh/yr. The main feedstock is Salix, the energy crop that gives the highest yield. This is helped by a low need for plant nutrients, water, the use of mechanized harvesting, and by short transport distances.

\section{Sustainability of Biomass Production for Bioenergy}

The growing diversity of uses and public expectations related to forests has led to the concept of sustainable forest management as a central purpose in controlling the management and use of forests. The concept of sustainable forest management is yet to be defined and measured, but over the past decade, intergovernmental and non-governmental organizations have worked to create measurable frameworks of criteria and indicators to define and characterize sustainable forest management so that different types of forest may contribute to the overall goals of sustainable forest management. Planted forests, for example, may be highly efficient for production of wood fibre and may also contribute to biodiversity conservation, water regulation, carbon sequestration and recreational benefits. Natural forests may have a greater role in biodiversity conservation, spiritual and cultural values and for non-timber forest products. The rapid expansion of biomass harvest and biomass energy development will raise many new issues in forest management. While many forest management processes will remain compatible with conventional timber harvesting, new aspects will need to be addressed. An assessment of these issues can be undertaken by examining the criteria of sustainable forest management and how they may be impacted by developments in the use of biomass.

To measure progress toward the sustainable management of forests several international processes use a system of criteria (values) and indicators (measurements of values) of sustainability on regional, national and international scales. The criteria and indicators of sustainable forest management assess the sustainability of forests by environmental criteria (health, productive capacity, biodiversity, soil, water, and carbon budgets, economic criteria (level of employment, price of wood and other forest products), and social criteria such as public participation in forest management decisions, the use of forests for spiritual and aesthetic activities. These same principles for natural forests are being applied to the production of biomass for energy.

Criteria and indicators are primarily tools to assess performance in forest management and are not inherently standards unless specific targets are set against the indicators. In most cases they are designed to provide information that will help in setting policy directions and strategies for management. At the national or even regional scale, biomass energy is only one part of the overall system of land use and forest management. At this level biomass energy is one of the products of the forest management system and contributes to the benefits and potential impacts that are monitored via the indicators. Specific sets or indicators for biomass energy are not likely to be needed.
Certification is another consideration which may soon affect the production of biomass for energy. Certification is an independent attestation that the products of forests are generated from sustainably managed lands. Certification is done to secure continued access to public forest lands through improved public acceptance of forest management activities coupled with reduced pressure from environmental groups. This is in the overall context of wood procurement policies that define sources from which companies or individuals will be able to obtain supplies of fibre. As the biomass community prepares for certification it must be aware of the problems with current terms and definitions that will define how we do business in the future. Energy from these production sources will sooner or later be offered to consumers as "green power" and will require the assurance that certification provides.

\section{Economic Sustainability of Biomass Production}

Biomass energy can have many positive economic benefits. Construction of a biomass energy facility can bring the economic equivalent of a medium-density fibreboard plant, or a sawmill, by creating a similar number of jobs. In addition, biomass energy from an integrated harvesting operation can improve the financial return from harvesting and make operations in previously marginal areas economically viable. The availability of biomass energy markets can also facilitate commercial thinning of planted forests where markets have not previously been able to use these products. The scale of biomass energy needed to make significant inroads on carbon dioxide emissions from fossil fuel-based electricity generation will, however, quickly saturate the capability of existing forest resources in many areas. In many cases there is a need to develop new planted forests, linked with the capacity of the generation facility.

In most biomass production systems the commercial value of biomass for energy is low compared to that of commercial products such as lumber, veneer, pulpwood and poles. Thus, the justification of wood energy is often done on the basis of environmental and social benefits rather than on conventional economics. For a forest residue harvesting operation to be economically viable, cost factors must be clearly understood and carefully controlled in design and operation. Harvesting and transport operations should target stands where conditions are favourable for recovery and the scale of operations should allow full utilization of equipment.

In the case of short-rotation plantations, which may be on public or private lands, an annual return is necessary-as important as for other crops. In many European countries where biomass use is more common than in North America, a support system of incentives and subsidies distorts (or supports!) the market. Markets for biomass in developed countries are limited by high capital and operating costs for combustion units despite incentives such as capital cost-sharing for the installation of commercial systems supplying building heat and taxation relief for the installation of electrical cogeneration systems. Other barriers include an imbalance between residue supply and energy demand coupled with high transportation costs and low calorific values for biomass fuels.

To complement environmental sustainability, harvesting technology needs to address economic concerns as well. At present, feedstock costs for biofuels in North America are low compared 
to their cost in Europe. While this provides limited returns to the producer/landowner, it may stimulate the use of biomass as it competes with fossil fuels for energy generation.

The expansion of plantation cultivation into previously agricultural land must be undertaken with consideration of the impacts on rural communities. In many areas there is a growing trend towards joint ventures, agro-forestry, or land leasing arrangements with farmers, so that rural communities are not displaced by expansion of planted forests. The potential opportunities for mixed forestry-biomass-carbon sequestration plantations may make tree farming an increasingly attractive economic proposition, particularly where carbon emissions trading occurs or where carbon taxes are introduced.

Policies and political priorities frequently change with the impact of new knowledge and information and shifts in public opinion. Future energy markets are likely to be less regulated than today and the forest energy industry more subject to market forces. In the near to medium future we can expect a price for carbon in response to demands from international protocols/treaties that will affect the cost/price of biomass production. Effective policies will need to be transparent, cost-effective in achieving objectives, and "fair" as regards renewable versus non-renewable energy systems. A stable policy environment and better harmonization among countries, particularly in relation to global environmental issues, can improve efficiency and the potential for increased forest energy use. It is essential that the promoters of bioenergy be aware of policy initiatives and responses, while themselves contributing to energy policies.

\section{Environmental Sustainability of Biomass Production}

Environmental issues surrounding the production of biomass are those which arise from managing many natural resources. Three of the more important are site productivity, biodiversity, and carbon stocks.

\section{Site productivity}

A commonly expressed environmental concern about bioenergy systems is that soil nutrients, organic matter and moistureholding capacity are depleted when biomass is removed. Many studies have shown that impacts on the inherent fertility of sites are a function of the intensity of harvest and the shortness of the rotation period. If biomass harvesting becomes more intensive, care must be taken to manage both nutrient pools and organic matter on plantation sites.

Protection of soil in any harvesting operation relates to careful operational practices that will reduce physical soil disturbance, compaction or removal of organic matter layers on the soil surface. In addition, where disturbance does occur, such as in the construction of roads and extraction tracks, there is a need to manage water flows and runoff to reduce contamination of streams and water bodies by soil and silt. In most cases, codes of practice or other measures are well-established and can be readily implemented for biomass harvesting in natural or planted forests.

Nitrogen and other elements are abundant in twigs and foliage so that harvesting all above-ground biomass has the potential to remove a large proportion of nutrients. However, under operational harvesting conditions, forest residues are never completely removed so such losses remain more potential than actu- al. Nutrient removals in biomass can also be minimized if foliage is allowed to dry and return to the site. These and other cultural practices improve nutrient cycling while enhancing the combustion value of the biomass.

Environmental concerns can also be alleviated if nutrients are returned to the forest after combustion. Nutrients (except for nitrogen) are concentrated in the ash, which can be spread back in the forest as a natural fertilizer and to counter-act acidification. Ash from firing combustion systems in which biomass is burned along with coal or other fossil fuels should not be used for fertilizer because of the presence of heavy metals from the coal. Other wastes, industrial and municipal biosolids/effluents can also be used to maintain and enhance soil quality. Environmental concerns arise from particulate pollution in smoke, although this can largely be avoided using clean state-of-the-art technologies.

Forest residues are also an important source of organic matter essential for maintaining soil structure and aeration. Normal residue harvesting practices remove a portion of the branches and tops but leave sufficient biomass to conserve organic matter and nutrients. Soil compaction, which reduces the extent and time of root growth can be minimized by operating when soils are dry and by avoiding repeated passes of heavy equipment.

Water yield is also an issue of concern. Forests regulate water yield by increasing water holding capacity of soils and by rainfall interception and transpiration. Increases in foliar biomass through intensified management of natural forests or through extension of planted forests leads to increased transpiration and reduced water flow but will help retain water on the site and reduce flooding.

Science-based studies of site productivity in unmanaged forests are at best able to indicate which areas should not be harvested for biomass. Sites where nutrients are limiting should not be harvested, or harvest should be limited to removal of stemwood. Avoiding harvesting on drought-stressed sites, and limiting removals to once per rotation also minimizes the impacts of harvesting on long-term productivity.

\section{Biodiversity}

Biodiversity concerns arise at all three levels recognized by policymakers - at the generic, species and landscape levels. Biodiversity conservation is a central issue to forest management. Increasing emphasis in managing natural forests is placed on conserving extant biodiversity by protecting unique ecosystems and critical habitat and balancing the vegetation structure, growth stages and forest ecosystem types over time. In managing planted forests there is emphasis on retaining patches or riparian corridors of natural vegetation, and in some cases reestablishing native vegetation as part of the overall plantation development.

Biomass harvesting from native forests will likely lead to more comprehensive utilization of woody biomass. In some ecosystems, this can mean, for example, removal of currently nonmerchantable stems, branches and bark. In some cases, this intensification of harvest can reduce the post-harvest level of habitat and shelter for wildlife relative to conventional harvesting. Planting can be managed to connect fragmented wildlife habitats, field and felling unit sizes can be altered, pesticides can be eliminated or reduced, ground vegetation encouraged, and species and age mixtures employed to create a diverse landscape. 
In planted forests, biomass energy may lead to shorter rotation periods in softwood and hardwood plantations. This may again reduce the habitat suitability of the planted forests for species of flora and fauna. As an example, a thirty-year rotation for hardwood sawlogs would begin to take on many of the characteristics of natural forests by late in the rotation. A three-year rotation for energy would have much more limited development of habitat.

\section{Greenhouse Gas Reduction}

Bioenergy systems offer significant possibilities for reducing greenhouse gas emissions when they are substituted for fossil fuel in energy production. Bioenergy systems can be considered as part of a closed carbon cycle, and so neutral with respect to carbon balance. When biomass replaces fossil fuels, it contributes to carbon sinks by not using fossil fuels for energy production. In the case of energy biomass plantations, additional benefits to the carbon cycle accrue by accumulating carbon in the soil. The recognition of this is one of the most powerful reasons for the use of bioenergy.

The UNFCCC and the Kyoto Protocol under the convention have increased the opportunities for carbon accounting and emissions accounting in many countries. A resurgence in biomass energy can be encouraged by the demand for alternatives to fossil fuel-based energy systems. In some cases, the substitution of biomass energy for fossil fuel-based energy will require effective carbon accounting in forest management. This accounting can be done separately by viewing the forest as a closed system where harvested biomass is replaced by natural regeneration or planting to retain the carbon pool, and the use of a systems approach studying the carbon balance and the impact of the biomass in offsetting fossil fuel energy. Such a system would analyze, on a full fuel-cycle basis, all processes involved in the use of bioenergy systems, with the aim of establishing overall greenhouse gas (GHG) balances. It would evaluate trade-offs between strategies of maximised carbon storage (afforestation, forest protection) and maximised fossil fuel substitution with biofuels. It would also calculate the changes in carbon storage in plants, debris and soils when biomass is grown and harvested. Changes may extend over longer periods after which a new equilibrium is reached, necessitating time-dependant analysis.

There are alternatives between biomass harvest and carbon storage in biomass; bioenergy options provide long-term benefits whereas afforestation is usually a temporary measure. Bioenergy provides irreversible mitigation effect by reducing carbon dioxide at source, but the use of biomass fuels may emit more carbon per unit of energy than fossil fuels if biomass fuels are derived from unsustainable land use practices and result in a reduction of biological carbon stocks.

Concerns have been raised that intensification of planted forest harvesting and shortening of rotation lengths may also lead to increases in insect pests, diseases and weeds. There are concerns that these planted forests may become infection sources for outbreaks in surrounding forests. Where genetically modified tree species are being used in high-intensity or short-rotation plantations, there is also the concern that these species will themselves escape into surrounding natural forests and become weeds or inter-breed with natural trees, in effect "polluting" the natural gene pool. Again, an intelligent approach to managing these issues can ensure that sustainability goals are met.
Highly efficient bioenergy systems are available using the newest technology. If managed properly, short rotation forests are a sustainable resource that can be renewed in perpetuity. They are $\mathrm{CO}_{2}$-neutral, and can help replace a finite and less environmentally friendly fossil fuel supply. Such a system can be used in combination with the disposal of sewage waste, enabling short-rotation crops to act as an effective soil ameliorator and biological filter. They may often be a good crop for unused or set-aside agricultural lands, where they can support a greater diversity of wild plants and animals than most agricultural crops, and at the same time provide a source of employment and social stability in rural communities.

\section{Social Sustainability of Biomass Production}

The essence of sustainability from a social aspect is how biomass production is perceived by society, and how different societies benefit from biomass production. Biomass production systems require people to operate them, involving considerations of rural employment, the idea of biomass and woodfuel production as a traditional activity, and the indirect impacts on people outside of producers and users. Public perceptions and values of forests form necessary parts of the socio-economic mix.

Biomass production provides direct and indirect employment with the socio-economic impacts varying with the scale of the operation. A landowner with a wood-fired heating system for his home and farm buildings will probably harvest his fuel supply from his own woodlot using his own labour. There are no wages involved, only " "sweat equity." The same landowner may also benefit from the sale of wood or from renting his equipment for production. Similarly, short-rotation crops may replace certain crops on unused land. In many countries, the concept of agro-forestry is becoming more widespread, with wood products considered another crop in addition to grains, vegetables or forage crops.

Most residue harvesting operations are conducted by contractors who might supply biomass for a small district heating plant, or who collectively supply larger plants. The impact on employment is primarily in rural areas, and this is often an important policy consideration where rural employment and rural depopulation are public policy goals. The need for employment and consequent self-sufficiency still exists and is increasingly difficult to satisfy in both the developed and developing world. In the developed world there remains a strong cultural tradition for the place of woodfuel biomass in energy supply. However, as the efficiencies of scale increase or as integrated harvesting systems are used, fewer people tend to be employed per volume of residues harvested.

When the factors of supply and demand are appropriate, new and novel approaches are possible. An example of this is agreement between wood users and landowners in western Canada where the demands of wood users and possibilities of supply from private landowners coincide. Wood users aim to grow nearly one-fifth of their wood supply on fibre farms and managed woodlots. This is done through flexible lease arrangements and grower agreements to supply on a rotation of 18-20 years, producing $275-350 \mathrm{~m}^{3} / \mathrm{ha}$; nearly double yields in unmanaged forests over a 70-80 year rotation.

Sometimes, cultural traditions are being revived by the increased use of woody biomass for bioenergy. In the boreal forest, many aboriginal communities have no year-round road or connections to the national electricity grid, and are depen- 
dent on diesel generators supplied by fuel flown or barged in at high cost. These communities are often surrounded by forest which could provide the necessary biomass and which would make the community more self-sufficient, reduce costs, provide employment, and integrate well with a forest-based culture. There are examples where a shift to locally produced bioenergy has been very successful and these successes need to be encouraged. Many communities near marginal agricultural land would also benefit from plantations of short-rotation woody crops.

Urban attitudes to biomass production are related to conventional forestry systems and agricultural issues generally, and to broader concerns for the environment. Better communication needs to be encouraged among all stakeholders to improve this situation.

Biomass energy developments will be strongly influenced by the policy environment and incentives put in place in society to spur a change to reduce net greenhouse gas emissions. Carbon taxes tend to be an interventionist approach and are likely needed only where government incentives combined with the market are unable to achieve the policy goal of emissions reductions. Consideration of the legal framework to ensure both a positive climate for investment in biomass energy and associated forest resources and, concurrently, the protection of the environment from particulates or other negative impacts is an important part of sustainable forest management.

\section{Conclusion}

There is increasing recognition of the local and global environmental advantages of bioenergy - the largest renewable energy source in use today representing nearly a billion tonnes of oil equivalent, a level comparable to that of natural gas, coal and electricity consumption. The trend towards cleaner, greener, smaller and more decentralized energy production facilities has a positive effect on demand for biomass energy. A diversification of public expectations for goods and services to be provided by forests has increased demands, and contribute to the development of sustainable forest management as a goal to be pursued by society. The issues of sustaining forest cover, slowing deforestation, regenerating natural forests, engaging in intensive forest mangement, improving the management of agricultural and rangeland soils can all be addressed through increasing our bioenergy component. The use of biomass to generate energy will provide continued greenhouse-gas benefits through substitution of biomass for fossil fuels and the possibility for additional carbon sequestration in plantations. Bioenergy production systems can also use biomass that would otherwise be unmerchantable, and plantations can be established in rural areas where land is becoming less suitable for agriculture and employment opportunities are limited.

Biomass for energy as a by-product of the growth of natural forest stands and plantations is recognized and used worldwide, and supported by science-based guiding principles developed to help ensure the economic, environmental and social sustainability of biomass production systems.

Biomass production systems operate on the premise that sustainability is the unifying concept that must underlie all components of forestry systems for energy production. The scientific underpinnings may require further extended study before we fully understand all the principles involved, and the technical details are complex and vary with geography, ecosystem and socio-economic conditions, but the guiding principles are understood and implementation is not limited by our current levels of knowledge.

The policy context within which biomass production is undertaken is important. There are many types of regulations, laws, policies, subsidies and taxes which affect biomass production systems. These include forest land availability, environmental and nature conservation, policies for extracting woodfuel, forest laws, forest industry operations, waste disposal laws, energy production from woodfuel, emission regulations, subsidies/financial incentives, and market considerations.

The concept of sustainability may be summed up in the North American aboriginal idea of "a forest for seven generations." The greatest span of time that any individual is likely to know in one lifetime is that represented by seven generationsfrom one's great-grandparents to one's great-grandchildren. If we each strive to uphold that principle from our own seven-generation span, learning from science and experience, and projecting scientifically on the basis of analysis and prediction, then we may achieve sustainability. These can assure us of bioenergy from sustainable forestry. 